\title{
Internet Access, Social Risk Factors, and Web-Based Social Support Seeking Behavior: Assessing Correlates of the "Digital Divide" Across Neighborhoods in The State of Maryland
}

\author{
Elham Hatef ${ }^{1,2} \oplus \cdot$ Xiaomeng Ma $^{1} \cdot$ Yahya Shaikh $^{3} \cdot$ Hadi Kharrazi $^{1} \cdot$ Jonathan P. Weiner $^{1} \cdot$ Darrell J. Gaskin $^{2}$
}

Received: 5 August 2021 / Accepted: 14 September 2021 / Published online: 19 September 2021

(c) The Author(s), under exclusive licence to Springer Science+Business Media, LLC, part of Springer Nature 2021

\begin{abstract}
We aimed to empirically measure the degree to which there is a "digital divide" in terms of access to the internet at the smallarea community level within the State of Maryland and the City of Baltimore and to assess the relationship and association of this divide with community-level SDOH risk factors, community-based social service agency location, and web-mediated support service seeking behavior. To assess the socio-economic characteristics of the neighborhoods across the state, we calculated the Area Deprivation Index (ADI) using the U.S. Census, American Community Survey (5-year estimates) of 2017. To assess the digital divide, at the community level, we used the Federal Communications Commission (FCC) data on the number of residential fixed Internet access service connections. We assessed the availability of and web-based access to community-based social service agencies using data provided by the "Aunt Bertha" information platform. We performed community and regional level descriptive and special analyses for ADI social risk factors, connectivity, and both the availability of and web-based searches for community-based social services. To help assess potential neighborhood linked factors associated with the rates of web-based social services searches by individuals in need, we applied logistic regression using generalized estimating equation modeling. Baltimore City contained more disadvantaged neighborhoods compared to other areas in Maryland. In Baltimore City, 20.3\% of neighborhoods (defined by census block groups) were disadvantaged with ADI at the 90th percentile while only $6.6 \%$ of block groups across Maryland were in this disadvantaged category. Across the State, more than half of all census tracts had 801-1000 households (per 1000 households) with internet subscription. In contrast, in Baltimore City about half of all census tracts had only 401-600 of the households (per 1000 households) with internet subscriptions. Most block groups in Maryland and Baltimore City lacked access to social services facilities (61\% of block groups at the 90th percentile of disadvantage in Maryland and 61.3\% of block groups at the 90th percentile of disadvantage in Baltimore City). After adjusting for other variables, a $1 \%$ increase in the ADI measure of social disadvantage, resulting in a 1.7\% increase in the number of individuals seeking social services. While more work is needed, our findings support the premise that the digital divide is closely associated with other $\mathrm{SDOH}$ factors. The policymakers must propose policies to address the digital divide on a national level and also in disadvantaged communities experiencing the digital divide in addition to other SDOH challenges.
\end{abstract}

Keywords Social determinants of health $\cdot$ Internet access $\cdot$ Digital divide $\cdot$ Community-based social services $\cdot$ Connected health

\section{Abbreviations}

$\begin{array}{ll}\text { ACS } & \text { American Community Survey } \\ \text { ADI } & \text { Area Deprivation Index }\end{array}$

COVID-19 Coronavirus Disease 2019

This article is part of the Topical Collection on Health Policy

Elham Hatef

ehatef1@jhu.edu

Extended author information available on the last page of the article

$\begin{array}{ll}\text { EHR } & \text { Electronic health records } \\ \text { FCC } & \begin{array}{l}\text { The U.S. Federal Communications } \\ \text { Commission }\end{array} \\ \text { GEE } & \begin{array}{l}\text { Generalized estimating equation } \\ \text { Mbps }\end{array} \\ \text { Megabits per second } \\ \text { SDOH } & \text { Social determinants of health }\end{array}$




\section{Introduction}

Digital technologies are an important means of gaining access to SDOH such as employment, housing, education, and social networks [1]. Their role in providing healthcare services in the form of connected health tools (e.g., telehealth services, patient portals to electronic health records, remote monitors, and mobile apps) is also growing. However, their impact on health at the population level can be limited by the lack of affordable internet connectivity and the underlying "digital divide".

A growing body of evidence has depicted the digital divide in large parts of the U.S. The divide is particularly acute among Americans living in rural communities where about 23 million people lack broadband access [2]. Living on tribal lands [3], older age, lower-income, or education are other factors contributing to less access to broadband service at home [4]. Moreover, the digital divide has led to significant disparities across the country in terms of access to connected health technology [2]. In addition to its impact on health, the divide might also exacerbate disparities in other SDOH such as limiting educational and employment opportunities [5].

The impact of the digital divide is critical in the context of the current COVID-19 pandemic. The use of telehealth services to address patients' needs during the pandemic has been unprecedented. The shift to virtual clinician/patient interaction has impacted not only the $\sim 5 \%$ of Americans [6] with confirmed COVID-19 infections but also every person coming in contact with the healthcare system. From mid-March through April 2020, the growth of telehealth went from $5 \%$ of all US in-person office-based medical visits per week to a reported $80 \%$ or higher [7]. Until new vaccines, treatments, and herd immunity are entrenched, the majority of COVID-19 and non-COVID-19 triage and care will be fully or partially electronic.

Recently, within the U.S. medical care context, there is increased appreciation that $\mathrm{SDOH}$, both at the community and personal level, represent key factors that must be considered when assessing and addressing the health of patients and populations. Some federal and professional organizations (i.e., FCC, American Public Health Association, American Medical Informatics Association) suggest that the lack of adequacy of digital access should be considered as a new type of SDOH risk factor or a "super-determinant of health" [8, 9] and FCC has started assessing the correlation of this new type of SDOH with health outcomes [10].

Such an approach to connectivity provides the opportunity to properly address the growing role of internet access in connecting patients to the care continuum and supporting patients' transition from the healthcare system to the community. It also provides support for the ongoing development of healthcare EHR infrastructure for patient care, population health, and for identification and referral of at-risk patients to community-based social services [8, 9].

But before this approach might be widely adopted, we need to gain empirical evidence regarding the association and interplay between the availability of internet connectivity services, standard SDOH measures, and social service agency availability and access at the neighborhood and regional level.

In this study, we measured the degree to which there is a digital divide in terms of access to internet connectivity services at the small-area community level within the State of Maryland and the City of Baltimore. For this assessment we used the FCC data on fixed internet access, a less utilized data source in healthcare studies for assessment of digital divide. Unlike other reports on internet access which assessed the connectivity for a limited number of participants responding to a survey [11], the FCC data provided the market-level information about the number of actual connections being subscribed by households. We used data on fixed internet access rather than broadband and/ or cellphone access as reported in other study, to reveal the immense disparities that currently exist in places where even lower speed internet connectivity was unavailable. We also assessed the association of this divide with community-level SDOH risk factors, using a composite measure of a number of evidencebased SDOH variables. For the first time, our study assessed the community-based social service agency locations, and web-mediated support service seeking behaviors in relation to the digital divided. We selected Maryland and Baltimore City because despite Maryland being the wealthiest state in the nation there are ongoing disparities and a wide range of challenges related to SDOH across the state and in Baltimore City $[12,13]$.

\section{Methods}

\section{Data source}

We used the ADI to assess the socioeconomic characteristics of the neighborhoods in Maryland and Baltimore City. ADI is a composite measure allowing for ranking of neighborhoods by the socioeconomic disadvantage in a region of interest. It includes variables for the domains of income, education, employment, and housing quality [14]. The ADI construction in our study was based on the U.S. Census, ACS 5-year estimates (2013-2017) [12] and the method introduced by Singh [15] To calculate ADI, we: (1) 
composed 17 ADI variables from identified 71 independent census variables, (2) summed up 17 ADI components weighted by Singh's score coefficients [15], and (3) scaled and shifted the factor values to have a mean of 100 and a standard deviation of 20 . We constructed ADI raw scores for 52 states at three geographical levels (i.e., ZIP codes, tracts, and block groups). We then sorted and ranked the ADIs across the nation for the geographic level of interest according to the score values. We selected Maryland ADI percentiles as the national ranks for different neighborhoods in Maryland comparing them to other neighborhoods across the country. The higher ADI percentiles represented more disadvantaged neighborhoods.

To characterize internet connectivity, we used FCC data on the number of residential fixed Internet access service subscriptions per 1,000 households based on December 2016 Form-477 broadband subscribership data [16]. Data included internet connections by census tract for "service at least 10 Mbps download and 1Mbps upload" [16].

We assessed access to community-based social services using Aunt Bertha's data [17]. Aunt Bertha provides a platform to make information related to community-based social services more accessible to those in need [17]. Their data included both supply and demand data up to 2018. Supply data included the list of community-based social services and their characteristics such as name and full address of the organization. Aunt Bertha's data also included the type of available services by each organization (i.e., food, housing, goods, transit, health, money, care, education, work, legal). Demand data included information on individuals (seekers) and organizations (healthcare workers) utilizing Aunt Bertha's service. The data also included number of searches by seekers and healthcare workers for available services in each ZIP code.

\section{Statistical analysis}

We performed descriptive and univariate analyses for ADI, connectivity variables, and those related to community-based social services. We assessed the digital divide, access to community-based social services, and the number of online searches for those services by seekers and healthcare workers for different categories of ADI. We defined different categories of ADI as neighborhoods at the $10^{\text {th }}$ percentile of disadvantage, neighborhoods at the $11^{\text {th }}$ to $89^{\text {th }}$ percentile of disadvantage, and neighborhoods at the $90^{\text {th }}$ percentile of disadvantage. We categorized internet connectivity to 5 groups based on the number of households with internet connection subscriptions in each census tract. The 5 selected groups included: category 1 (0-200 out of 1000 households with internet access), category 2 (201-400 households), category 3 (401-600 households), category 4 (601-800 households), and category 5 (801-1000 households). We assessed access to communitybased social services based on the social services density (i.e., number of social services facilities in the community using unique facility address) and social services diversity (i.e., number of different social services such as housing, food, transportation provided by all unique facilities in each geographic area of interest). We defined seekers of each service as the number of individuals in each zip code searching for social services and healthcare workers as the number of healthcare workers in each zip code searching for social services.

We also assessed the correlation between ADI and connectivity. To assess factors affecting the number of searches for social services by individuals in need of those services, we applied logistic regression using GEE model with robust variance [18]. We included the connectivity variable, social services density, and ADI national rank as a group or cluster-level variables representing ZIP code level measurements. We also adjusted the model for the population size of a ZIP code. The GEE model provided the unbiased estimates of the parameters while adjusted for the effects of the geographically-clustered data.

Supplement Fig. 1 presents a framework addressing the relationship among internet access, other $\mathrm{SDOH}$ risk factors and social services density and diversity.

\section{Spatial analysis}

For the spatial exploratory data analysis, we presented an overlaying map of connectivity and ADI and maps of community-based social services and ADI in Baltimore City [19]. We presented connectivity and community-based social services as categorical variables and aggregated the numbers for each geographic level of interest (i.e., census tract for connectivity and block group for social services) and mapped the distribution of each variable in Baltimore City. We provided the same maps for Maryland in the Supplement Figs. 2 and 3. We conducted all analyses in R version 3.3.1 (using the GEE package for modeling) [20] and used the ArcGIS ${ }^{\circledR}$ software to generate the maps.

We did not obtain institutional review board approval due to the use of publicly available, de-identified data, per usual institutional policy. We obtained a data use agreement with Aunt Bertha to access their supply data, and the de-identified demand data on search history by individuals (seekers) and organizations (healthcare workers) utilizing Aunt Bertha's service. The demand data included only the location of the search on a ZIP code level.

\section{Results}

\section{Area deprivation index}

We assessed the distribution of ADI across Maryland and Baltimore City on the block group level. The percentage of 
block groups with middle ADI national rank (at the $11^{\text {th }}-89^{\text {th }}$ percentile) was relatively similar across Maryland and in Baltimore City (3,075 out of 3,901 (78.8\%) block groups in Maryland and 500 out of 649 (77.0\%) block groups in Baltimore City). Baltimore City contained fewer advantaged neighborhoods at $10^{\text {th }}$ percentile and more disadvantaged neighborhoods at $90^{\text {th }}$ percentile of ADI compared to other areas in Maryland. Only 17 (2.6\%) of block groups in Baltimore City were with an ADI at the $10^{\text {th }}$ percentile while 567 (14.5\%) of block groups in Maryland were in this category. 132 (20.3\%) of Baltimore City block groups were disadvantaged with ADI at the $90^{\text {th }}$ percentile while only $259(6.6 \%)$ of block groups across Maryland were in this category.

\section{Internet access and digital divide}

Table 1 presents the residential fixed internet access service connection for different ADI categories across Maryland and Baltimore City on a census tract level. In Maryland, 52.1\% of all census tracts were in category 5 of connectivity with 801-1000 of their households (per 1000 households) having access to service of at least 10Mbps download and 1Mbps upload. In affluent neighborhoods of Maryland (those at the $10^{\text {th }}$ percentile of ADI) $86.1 \%$ of census tracts were in category 5 of connectivity; however, in disadvantaged neighborhoods (those at the $90^{\text {th }}$ percentile of ADI) only $13.1 \%$ of census tracts were in category 5 of connectivity.

In Baltimore City, $45.0 \%$ of all census tracts were in category 3 of connectivity with 401-600 of their households (per 1000 households) having access to service of at least $10 \mathrm{Mbps}$ download and 1Mbps upload. In affluent neighborhoods of Baltimore City (those at the $10^{\text {th }}$ percentile of ADI) connectivity was more homogenous with $100 \%$ of census tracts being in category 4 of connectivity with $601-800$ of their households (per 1000 households) having access to services at least 10Mbps download and $1 \mathrm{Mbps}$ upload. In disadvantaged neighborhoods (those at the $90^{\text {th }}$ percentile of ADI), $71.9 \%$ of census tracts were in category 2 of connectivity with only 201-400 of their households (per 1000 households) having access to services at least $10 \mathrm{Mbps}$ download and $1 \mathrm{Mbps}$ upload. The difference in internet connectivity subscriptions was statistically significant on a census tract comparison at the 10th percentile and 90th percentile of ADI $(\mathrm{p}<0.001)$ in Maryland and Baltimore City. The census tracts in the middle risk category (those at the $11^{\text {th }}$ to $89^{\text {th }}$ percentile of ADI) in Maryland and Baltimore City had a relatively similar pattern of access to services to the census tracts at the $10^{\text {th }}$ percentile of ADI.

We also assessed the correlation between ADI and residential fixed internet access service connection in Maryland and Baltimore City. We detected a high negative correlation
Table 1 Residential Fixed Internet Access Service Connection in Maryland and Baltimore City by Different Categories of Area Deprivation Index

\begin{tabular}{|c|c|c|c|c|c|c|c|c|c|}
\hline & \multicolumn{2}{|c|}{$\begin{array}{l}\text { All Census } \\
\text { Tracts }\end{array}$} & \multicolumn{2}{|c|}{$\begin{array}{l}\text { At the } 10^{\text {th }} \\
\text { Percentile (Low } \\
\text { Risk) }\end{array}$} & \multicolumn{2}{|c|}{$\begin{array}{l}\text { At the } 11^{\text {th }}-89^{\text {th }} \\
\text { Percentile }\end{array}$} & \multicolumn{2}{|c|}{$\begin{array}{l}\text { At the } 90^{\text {th }} \\
\text { Percentile } \\
\text { (High Risk) }\end{array}$} & $\begin{array}{l}\text { p-value } \\
{\text { (Chi-square })^{\mathrm{a}}}\end{array}$ \\
\hline Category $1(0-200)$ & 10 & $0.7 \%$ & 0 & $0.0 \%$ & 2 & $0.2 \%$ & 8 & $13.1 \%$ & $<0.001$ \\
\hline Category $2(201-400)$ & 92 & $6.6 \%$ & 0 & $0.0 \%$ & 64 & $5.6 \%$ & 28 & $45.9 \%$ & \\
\hline Category $3(401-600)$ & 201 & $14.4 \%$ & 2 & $1.1 \%$ & 189 & $16.5 \%$ & 10 & $16.4 \%$ & \\
\hline Category 4 (601-800) & 365 & $26.2 \%$ & 24 & $12.8 \%$ & 334 & $29.1 \%$ & 7 & $11.5 \%$ & \\
\hline Category 5 (801-1000) & 726 & $52.1 \%$ & 161 & $86.1 \%$ & 557 & $48.6 \%$ & 8 & $13.1 \%$ & \\
\hline Total & 1397 & & 187 & & 1146 & & 61 & & \\
\hline \multicolumn{10}{|l|}{ Baltimore City $^{\mathrm{b}}$} \\
\hline Category $1(0-200)$ & 2 & $1.0 \%$ & 0 & $0.0 \%$ & 0 & $0.0 \%$ & 2 & $6.2 \%$ & $<0.001$ \\
\hline Category $2(201-400)$ & 58 & $29.0 \%$ & 0 & $0.0 \%$ & 35 & $21.5 \%$ & 23 & $71.9 \%$ & \\
\hline Category 3 (401-600) & 90 & $45.0 \%$ & 0 & $0.0 \%$ & 84 & $51.5 \%$ & 6 & $18.8 \%$ & \\
\hline Category 4 (601-800) & 30 & $15.0 \%$ & 5 & $100.0 \%$ & 24 & $14.7 \%$ & 1 & $3.1 \%$ & \\
\hline Category 5 (801-1000) & 20 & $10.0 \%$ & 0 & $0.0 \%$ & 20 & $12.3 \%$ & 0 & $0.0 \%$ & \\
\hline Total & 200 & & 5 & & 163 & & 32 & & \\
\hline
\end{tabular}

ADI Area Deprivation Index, Mbps Megabits per second

*ADI: Area Deprivation Index - using national ranking for neighborhoods in Maryland and Baltimore City on a census tract level based on American Community Survey 2013-2017, 5-year estimate. Higher national rank represented more disadvantaged neighborhoods

${ }^{\text {a }}$-values comparing neighborhoods at $10^{\text {th }}$ percentile and $90^{\text {th }}$ percentile of ADI

${ }^{\mathrm{b}}$ The number and percentage of residential fixed Internet access service connection (at least 10Mbps download and $1 \mathrm{Mbps}$ upload) per 1,000 households by census tract. The rows with total numbers reflect the number of census tracts (out of all census tracts in Maryland and Baltimore City) with available data on service connection 
between ADI and internet connectivity. The correlation coefficient was -0.7535 in Maryland and -0.6529 in Baltimore City. The correlation coefficients represented a decrease in internet connectivity by an increase in ADI's national rank (more disadvantaged neighborhoods). Both correlation coefficients were statistically significant $(\mathrm{p}<0.001)$.

\section{Community-based social services}

Social services density and diversity varied across Maryland and Baltimore City (Table 2). In general, most block groups in Maryland and Baltimore City lacked access to any social service facilities. For instance, $61.0 \%$ of block groups at the $90^{\text {th }}$ percentile of ADI in Maryland and $61.3 \%$ in Baltimore City did not have any social service facilities. But block groups at the $90^{\text {th }}$ percentile of ADI had higher social services density and diversity of services compared to block groups at the $10^{\text {th }}$ percentile of ADI. For instance, $1.9 \%$ of block groups at the $90^{\text {th }}$ percentile of ADI in Maryland had the highest service density (10 or more facilities) compared to only $0.2 \%$ of block groups at the $10^{\text {th }}$ percentile of ADI. In Baltimore City, $2.3 \%$ of block groups at the $90^{\text {th }}$ percentile of ADI had the highest service density compared to $0.0 \%$ of
Table 2 Availability of Community-Based Social Services in Maryland and Baltimore City by Different Categories of Area Deprivation Index

\begin{tabular}{lllll}
\hline All Block Groups & $\begin{array}{l}\text { At the } 10^{\text {th }} \text { Per- } \\
\text { centile } \\
\text { (Low Risk) }\end{array}$ & $\begin{array}{l}\text { At the } 11^{\text {th }}-89^{\text {th }} \\
\text { Percentile }\end{array}$ & $\begin{array}{l}\text { At the } 90^{\text {th }} \\
\text { Percentile } \\
\text { (High Risk) }\end{array}$ & $\begin{array}{l}\text { p-value } \\
\text { (Chi-square) }\end{array}$ \\
\hline
\end{tabular}

State of Maryland

Social Services Density per 1000 Residents $^{\mathbf{b}}$

$\begin{array}{llllllllll}0 & 2545 & 65.2 \% & 389 & 68.5 \% & 1998 & 64.8 \% & 158 & 61.0 \% & <0.001 \\ 1-4 & 1282 & 32.9 \% & 174 & 30.6 \% & 1023 & 33.2 \% & 86 & 33.2 \% & \\ 5-9 & 63 & 1.6 \% & 3 & 0.6 \% & 49 & 1.7 \% & 10 & 3.9 \% & \\ >=10 & 11 & 0.3 \% & 1 & 0.2 \% & 5 & 0.2 \% & 5 & 1.9 \% & \end{array}$

Social Services Diversity per 1000 Residents ${ }^{\mathbf{c}}$

$\begin{array}{llllllllll}0 & 2545 & 65.2 \% & 389 & 68.0 \% & 1998 & 65.0 \% & 158 & 61.0 \% & <0.001 \\ 1-4 & 894 & 22.9 \% & 141 & 25.0 \% & 710 & 23.1 \% & 43 & 16.6 \% & \\ 5-9 & 247 & 6.3 \% & 19 & 3.4 \% & 202 & 6.6 \% & 26 & 10.0 \% & \\ 10-19 & 137 & 3.5 \% & 14 & 2.5 \% & 108 & 3.5 \% & 15 & 5.8 \% & \\ >=20 & 78 & 2.0 \% & 4 & 0.8 \% & 57 & 1.9 \% & 17 & 6.6 \% & \\ \text { Total } & 3901 & & 576 & & 3075 & & 259 & & \end{array}$

Baltimore City

Social Services Density per 1000 Residents ${ }^{\mathbf{b}}$

$\begin{array}{llllllllll}0 & 409 & 63.0 \% & 14 & 82.3 \% & 314 & 62.8 \% & 81 & 61.3 \% & 0.035 \\ 1-4 & 218 & 33.6 \% & 3 & 17.6 \% & 174 & 34.8 \% & 41 & 31.1 \% & \\ 5-9 & 17 & 2.6 \% & 0 & 0 \% & 10 & 2.0 \% & 7 & 5.3 \% & \\ >=10 & 5 & 0.8 \% & 0 & 0 \% & 2 & 0.4 \% & 3 & 2.3 \% & \end{array}$

Social Services Diversity per 1000 Residents ${ }^{\mathbf{c}}$

$\begin{array}{llllllllll}0 & 409 & 63.0 \% & 14 & 82.3 \% & 314 & 62.8 \% & 81 & 61.3 \% & 0.338 \\ 1-4 & 105 & 16.2 \% & 2 & 11.8 \% & 88 & 17.6 \% & 15 & 11.4 \% & \\ 5-9 & 73 & 11.2 \% & 0 & 0 \% & 56 & 11.2 \% & 17 & 12.9 \% & \\ 10-19 & 34 & 5.2 \% & 1 & 5.9 \% & 24 & 4.8 \% & 9 & 6.8 \% & \\ >=20 & 28 & 4.3 \% & 0 & 0 \% & 18 & 3.6 \% & 10 & 7.6 \% & \\ \text { Total } & 649 & & 17 & & 500 & & 132 & & \end{array}$

The rows with total numbers reflect the number of block groups (out of all block groups in Maryland and Baltimore City) with available data on social services facilities

$A D I$ Area Deprivation Index

*ADI: Area Deprivation Index - using national ranking for neighborhoods in Maryland and Baltimore City on a block group level based on American Community Survey 2013-2017, 5-year estimate. Higher national rank represented more disadvantaged neighborhoods

${ }^{\text {a }} \mathrm{p}$-values comparing neighborhoods at $10^{\text {th }}$ percentile and $90^{\text {th }}$ percentile of ADI

${ }^{b}$ Number and percentage of social services facilities in the community using facility address per 1000 households by block group and ADI in Maryland and Baltimore City

${ }^{c}$ Number and percentage of different types of social services (e.g., housing, food, transportation) provided by all facilities in each neighborhood per 1000 households by block group and ADI in Maryland and Baltimore City 
block groups at the 10th percentile of ADI. In terms of social services diversity, among block groups at the $90^{\text {th }}$ percentile of ADI, only 6.6\% in Maryland and 7.6\% in Baltimore City had high service diversity (20 or more services).

Table 3 presents the number of online searches for community-based social services by consumer seekers (individuals searching for social services) and workers (healthcare workers searching for social services) in each zip code. Overall, more individuals and healthcare workers searched for social services in Baltimore City compared to other areas in Maryland. For instance, only $7.1 \%$ of ZIP codes in Maryland had 20 or more individuals searching for social services while in Baltimore City $19.4 \%$ of ZIP codes had 20 or more individuals searching for those services.
Table 3 Number of Online Searches (Per ZIP Code) for Community-Based Social Services per 1000 Residents by Different Categories of Area Deprivation Index in Maryland and Baltimore City ${ }^{*}$

\begin{tabular}{|c|c|c|c|c|c|}
\hline $\begin{array}{l}\text { Online } \\
\text { Searches } \\
\text { (per 1,000 } \\
\text { residents) }\end{array}$ & $\begin{array}{l}\text { All ZIP Codes } \\
(\mathrm{N}, \%)\end{array}$ & $\begin{array}{l}\text { At the } 10^{\text {th }} \\
\text { Percentile } \\
\text { (N,\%) } \\
\text { (Low Risk) }\end{array}$ & $\begin{array}{l}\text { At the } 11^{\text {th }}-89^{\text {th }} \\
\text { Percentile }(\mathrm{N}, \%)\end{array}$ & $\begin{array}{l}\text { At the } 90^{\text {th }} \\
\text { Percentile (N,\%) } \\
\text { (High Risk) }\end{array}$ & $\begin{array}{l}\text { p-value } \\
\text { (Chi-square) }^{\mathrm{a}}\end{array}$ \\
\hline
\end{tabular}

State of Maryland

Consumer Seekers ${ }^{\mathrm{b}}$

\begin{tabular}{llllllllll}
0 & 158 & $33.8 \%$ & 8 & $16.0 \%$ & 53 & $15.2 \%$ & 26 & $37.1 \%$ & $<0.001$ \\
$1-5$ & 193 & $41.2 \%$ & 30 & $60.0 \%$ & 145 & $41.7 \%$ & 18 & $25.7 \%$ & \\
$6-10$ & 91 & $19.4 \%$ & 9 & $18.0 \%$ & 73 & $21.0 \%$ & 9 & $12.9 \%$ & \\
$11-20$ & 64 & $13.7 \%$ & 2 & $4.0 \%$ & 53 & $15.2 \%$ & 9 & $12.9 \%$ & \\
$>20$ & 33 & $7.1 \%$ & 1 & $2.0 \%$ & 24 & $6.9 \%$ & 8 & $11.4 \%$ & \\
Total & 539 & & 50 & & 348 & & 70 & & \\
\multicolumn{2}{l}{ Healthcare } & Workers as Agents & & & & & & & \\
0 & 299 & $63.9 \%$ & 35 & $70.0 \%$ & 212 & $60.9 \%$ & 52 & $74.3 \%$ & 0.048 \\
1 & 96 & $20.5 \%$ & 10 & $20.0 \%$ & 83 & $23.9 \%$ & 3 & $4.3 \%$ & \\
2 & 21 & $4.5 \%$ & 1 & $2.0 \%$ & 19 & $5.5 \%$ & 1 & $1.4 \%$ & \\
3 & 15 & $3.2 \%$ & 1 & $2.0 \%$ & 11 & $3.2 \%$ & 3 & $4.3 \%$ & \\
$>3$ & 37 & $7.9 \%$ & 3 & $6.0 \%$ & 23 & $6.6 \%$ & 11 & $15.7 \%$ & \\
Total & 468 & & 50 & & 348 & & 70 & &
\end{tabular}

Baltimore City

Consumer Seekers ${ }^{\mathrm{b}}$

$\begin{array}{llllllllll}0 & 2 & 6.5 \% & 0 & 0.0 \% & 1 & 4.8 \% & 1 & 10.0 \% & \text { NA } \\ 1-5 & 0 & 0.0 \% & 0 & 0.0 \% & 0 & 0.0 \% & 0 & 0.0 \% & \\ 6-10 & 9 & 29.0 \% & 0 & 0.0 \% & 9 & 42.9 \% & 0 & 0.0 \% & \\ 11-20 & 14 & 45.2 \% & 0 & 0.0 \% & 6 & 28.6 \% & 6 & 60.0 \% & \\ >20 & 6 & 19.4 \% & 0 & 0.0 \% & 3 & 14.3 \% & 3 & 30.0 \% & \\ \text { Total } & 31 & & 0 & & 19 & & 10 & & \end{array}$

Healthcare Workers as Agents ${ }^{\mathrm{c}}$

\begin{tabular}{clllllllll}
0 & 2 & $6.5 \%$ & 0 & $0.0 \%$ & 1 & $4.8 \%$ & 1 & $10.0 \%$ & NA \\
1 & 11 & $35.5 \%$ & 0 & $0.0 \%$ & 9 & $42.9 \%$ & 2 & $20.0 \%$ & \\
2 & 3 & $9.7 \%$ & 0 & $0.0 \%$ & 3 & $14.3 \%$ & 0 & $0.0 \%$ & \\
3 & 4 & $12.9 \%$ & 0 & $0.0 \%$ & 3 & $14.3 \%$ & 1 & $10.0 \%$ & \\
$>3$ & 11 & $35.5 \%$ & 0 & $0.0 \%$ & 5 & $23.8 \%$ & 6 & $60.0 \%$ & \\
Total & 31 & & 0 & & 21 & & 10 & & \\
\hline
\end{tabular}

The rows with total numbers reflect the number of ZIP codes (out of all ZIP codes in Maryland and Baltimore City) with available data on the number of online searches by consumer seekers and healthcare workers

ADI Area Deprivation Index

*ADI: Area Deprivation Index - using national ranking for neighborhoods in Maryland and Baltimore City on a zip code level based on American Community Survey 2013-2017, 5-year estimate. Higher national rank represented more disadvantaged neighborhoods

${ }^{\text {a }}$-values comparing neighborhoods at $10^{\text {th }}$ percentile and $90^{\text {th }}$ percentile of ADI. The $\mathrm{p}$-values are not available in Baltimore City due to frequent cells with 0 value

${ }^{b}$ Number of individuals searching for social services in each zip code

${ }^{\mathrm{c}}$ Number of healthcare workers searching for social services in each zip code 
For ZIP codes at $90^{\text {th }}$ percentile of ADI across Maryland, only $11.4 \%$ of those ZIP codes had 20 or more individuals searching for social services; however, in Baltimore City $30 \%$ of those ZIP codes had 20 or more individuals searching for those services.

Table 4 presents the results of the GEE model. We assessed different factors impacting the number of searches for social services by individuals (seekers). After adjusting for other variables, a one-percentile increase in ADI (going from a less disadvantaged neighborhood to a more disadvantaged one) resulted in a 1.7 increase in the number of individuals seeking social services $(p$-value $=0.015$ ). Also, a 1-unit increase in the social services density in each ZIP code resulted in an 8.9 increase in the number of individuals seeking those services ( $p$-value $<0.001$ ). Lastly, a 1-unit increase in the number of households with residential fixed internet access connection resulted in a 5.7 decrease in the number of individuals seeking those services but the association was not statistically significant $(\mathrm{p}$-value $=0.789)$.

\section{Spatial analysis}

Figure 1 presents residential fixed internet access service connections per 1000 households by census tract in Baltimore City. The distribution of connectivity followed a similar pattern as ADI with neighborhoods in east and west Baltimore (neighborhoods at the 90th percentile of ADI) experiencing less connectivity and those in the downtown area and north Baltimore (neighborhoods at the 10th percentile of ADI) expressing more connectivity. Mapping of social services density and diversity in Baltimore City (Fig. 2) presented a concentration of services mostly in the Baltimore City downtown area. See Supplement Figs. 2 and 3 for similar maps for Maryland.

Table 4 GEE Model Assessing Factors Affecting Seeking for Social Services in Maryland*

\begin{tabular}{lccc}
\hline Variables & Coefficient & $95 \%$ CI & p-value \\
\hline ADI (national rank) & 1.7 & $0.3,3.0$ & 0.015 \\
Residential Fixed Internet $_{\quad \text { Access Service Connection }}{ }^{\text {a }}$ & -5.7 & $-47.9,36.4$ & 0.789 \\
Social Services Density $^{\text {Socity }}$ & 8.9 & $4.7,13.2$ & $<0.001$ \\
\hline
\end{tabular}

R-squared for GEE model fitness was 0.500 , presenting the proportion of variation explained by the model

$A D I$ Area Deprivation Index, $C I$ Confidence Interval, GEE Generalized Estimating Equation

*The model is adjusted for the population size of each ZIP code

${ }^{a}$ The number of residential fixed Internet access service connections per 1,000 households by census tract

\section{Discussion}

\section{Overall findings}

The Healthy People 2020 report has set several objectives for Health Communication and Health Information Technology [21]. Among those objectives were "to increase the proportion of individuals with access to the internet to $75.4 \%$, a $10 \%$ improvement over the percentage observed in 2007 (68.5\%)" and "to increase the proportion of persons who use the Internet to keep track of personal health information to $15.7 \%$, a $10 \%$ improvement over the percentage observed in 2007 (14.3\%)" [21].

Despite some improvements in health information technology, a growing body of evidence has revealed an underlying digital divide that impacts health access and outcomes. Besides, evidence has shown disparities in using eHealth information through the Internet or the availability of patient portals through healthcare systems [22]. We detected placebased disparities in internet access. In our study, the internet access was statistically significantly correlated with ADI. Indeed, comparing advantaged neighborhoods to disadvantaged ones showed that internet access decreased by increasing ADI's percentile (e.g., national ranks). Affluent neighborhoods in Maryland and Baltimore City presented higher levels of connectivity for the majority of their households while in the disadvantaged neighborhoods fewer households had internet access.

FCC defines broadband connectivity as "service at a minimum of 25Mbps download and 3Mbps upload" [23]. We did not use data on broadband connectivity. Instead, we used the data on internet subscriptions, defined as the number of residential fixed Internet access service connections per 1,000 households for "service at least $10 \mathrm{Mbps}$ download and $1 \mathrm{Mbps}$ upload" [15]. The reason was that firstly data on broadband connectivity are not available at the geographically granular level (e.g., census tract) due to market competition concerns from internet service providers. If data become available at a geographically granular level (e.g., census tract or block group level) for 25/3Mbps, using 25/3Mbps plus 10/1Mbps data would be ideal to present the gravity of the digital divide. Secondly, looking at the $10 / 1 \mathrm{Mbps}$ is useful in revealing places where even lower speed internet connectivity is unavailable. Just looking at the subscription to $25 / 3 \mathrm{Mbps}$ would fail to reveal the immense disparities that currently exist.

Moreover, the estimates for internet subscriptions at the $10 \mathrm{Mbps}$ levels are more accurate since they are market-level data about the number of actual connections being subscribed by households in a region. Broadband access data is prone to overestimation because a provider that reports deployment of a particular technology and 
bandwidth in a geographic area may not necessarily offer that service everywhere in that area, but since the unit of data is at a geographic level the whole area may be artificially seen as having access to the broadband service. Also, there is a level of subjectivity to the actual availability of access since in the mandated reporting in FCC Form-477 a service provider can report geographic areas in which they potentially can offer service in addition to where they do provide the service, which can lead to overestimation of broadband access. Therefore, the internet subscription at $10 \mathrm{Mbps}$ is more accurate in terms of what is available at homes in an area.

One place where broadband access data is useful given its susceptibility for overestimate is its specificity: where access is not reported, it is highly probable that the broadband access does not exist. Therefore, while internet subscriptions (10Mbps) can be used to characterize the digital divide from the perspective of availability, the highly specific broadband access can be used to characterize very accurately where broadband is not available. Combining all of the data elements (subscription at 10Mbps, access at $25 / 3 \mathrm{Mbps}$, and access at different levels) is very useful in looking at and understanding the digital divide from multiple vantage points to give a clearer picture of the lived experience of communities.

We used data on fixed internet access (i.e., the internet connection using radio waves to provide a location with broadband internet access instead of using cables or a satellite connection [24]) and did not include data on mobile connectivity (i.e., a communication network where the last link is wireless [25]). While about 1-in-five adult Americans currently rely on smartphones for online access instead of a home fixed broadband connection and the reliance on smartphones and mobile connections is especially common among younger adults, non-whites, and lower-income Americans [5]. The types of applications that can be utilized over a fixed broadband connection are very different than applications that can be utilized over a mobile connection with data-limit considerations. For evaluating the digital divide, if a mobile connection is considered equivalent to fixed broadband then it would serve to hide disparities. Data-intensive health applications (e.g. downloading personal health records, multimedia for telehealth purposes, and other connected health activities that are a data sink) are not as easily and frequently accessible to those with mobile-only connections. In characterizing the connectivity environment in the US and in the recommendations to distinguish fixed from mobile connectivity FCC has recognized the critical need of each type of connectivity (fixed and mobile) but has also acknowledged the key differences in their capabilities and consumer behaviors [2].

While fixed and mobile connections can both be independently evaluated as different dimensions of a digital divide, combining them both will lead to an artificial narrowing of the digital divide and a more optimistic picture than is warranted. The fact that vulnerable populations tend to make up a disproportionate portion of the "mobile-only" population [5] illustrates the width of the digital divide in that there are limitations on the resources that "mobileonly" consumers can access that are otherwise available to people with fixed connection access. The services that can be accessed through a fixed connection are not the same as that can be accessed through a mobile connection, particularly for low-income communities that rely on severe data restricted lifeline-program subsidized mobile phones. Additionally, there is no standard for "mobile broadband", and making a comparison or inclusion with fixed broadband is not advisable since speed rates would be quite different.

\section{Comparing with past studies}

Greenberg-Worisek et al. [11] used the National Cancer Institute's (NCI) Health Information National Trends Survey (HINTS) to assess progress toward Healthy People 2020 goals on internet access using broadband. They presented an increase in the number of users having broadband access between 2003 and 2011 (from 32.83\% to $77.87 \%$ ), but the access has declined since then (55.93\% in 2017). They also identified statistically significant disparities for broadband access with older adults, women, those with low income, and residents of rural areas having less access [11]. Our results were similar to Greenberg-Worisek et al. study [11] in terms of place-based disparities in access to the internet.

Other studies have assessed disparities in using eHealth technology and the impact of broadband access on health. For instance, a study at the University of New Mexico explored the use of eHealth cancer prevention information among patients and caregivers attending a minority-serving oncology clinic. Less than half of their respondents (44.4\%) identified eHealth information as their major source of information for cancer prevention. Older adults, those with lower education, and Spanish speaking patients were less likely to use eHealth [26]. Woods et al. [22], assessed whether having broadband at home would affect the short-term and longterm use of the patient portal and identified patients using high-speed broadband at home having significantly higher patient portal usage. While the relationship might not be causal and a long list of mediators might have affected this effect it presented an association between broadband access and patient portal usage.

\section{Digital divide as a super-determinant of health}

The impact of digital divide goes beyond access to health information and communications with the healthcare providers. Qualitative work has shown that disrupted access 
to information and communications technologies also disrupted access to social services and social support [27]. We did not have access to the data on the use of eHealth technology. Instead, we assessed how internet access would impact searching for community-based social services while considering the place-based disparities represented by the ADI. We first assessed the distribution of community-based social services and service diversity in Maryland and Baltimore City. While neighborhoods at the $90^{\text {th }}$ percentile of ADI presented a slight increase in the social services density and diversity comparing to the neighborhoods at the $10^{\text {th }}$ percentile of ADI, the majority of disadvantaged neighborhoods in Maryland and Baltimore City lacked access to those facilities.

Mapping the social services density and diversity in Maryland (see Supplement Fig. 3) and Baltimore City (Fig. 2) also presented the same results. The overlaying maps (Figs. 1 and 2) provided a visual aid to assess the distribution of internet access and community-based social services in relation to the socioeconomic status of a neighborhoods represented by ADI. The side by side comparison of maps for internet access and community-based social services helped us to identify disadvantaged neighborhoods where lack of internet access and social services added to the challenges
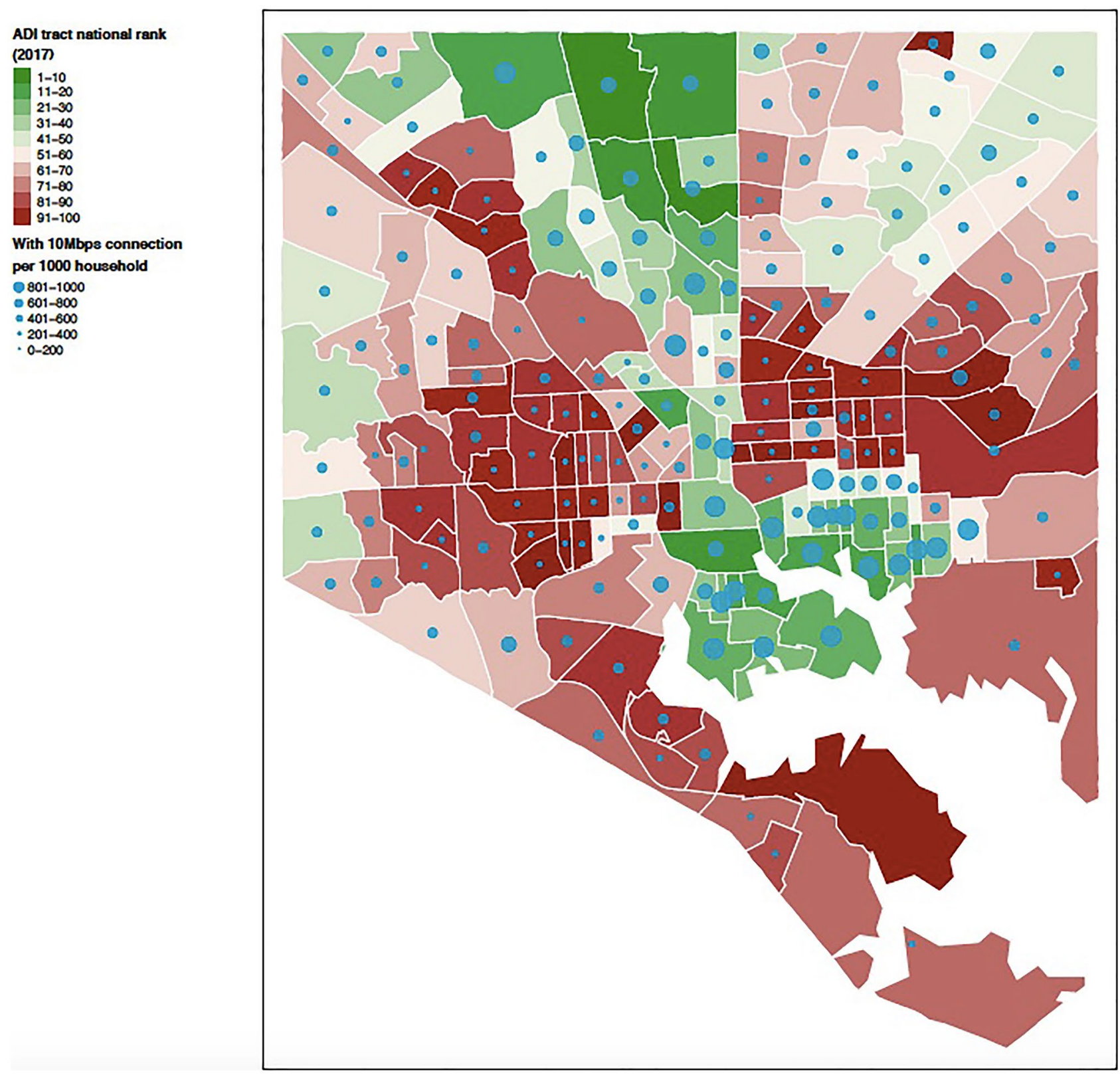

Fig. 1 Overlaying Maps of Residential Fixed Internet Access Service Connection per 1000 Households by Census Tract and ADI in Baltimore City 

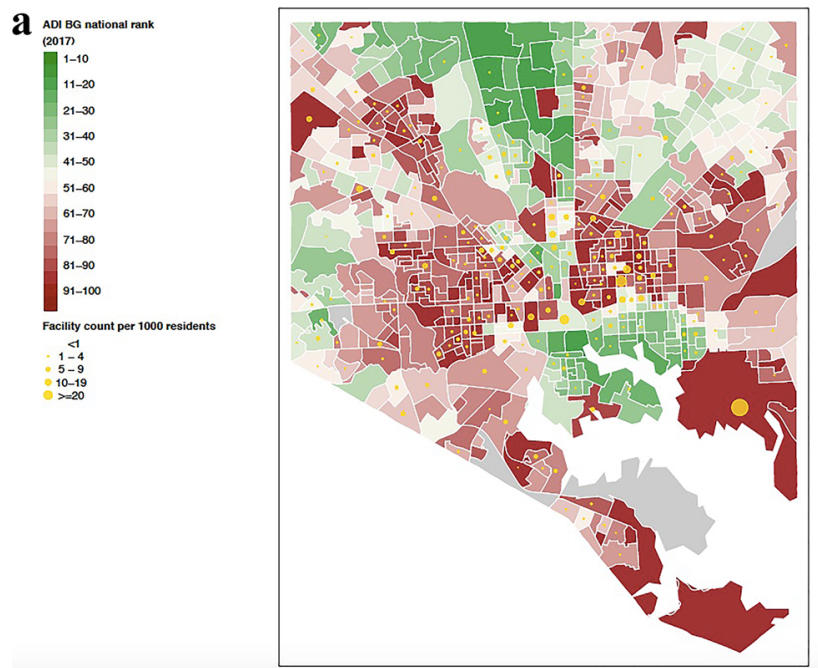

Fig. 2 Overlaying Maps of Community-Based Social Services per 1000 Residents by Block Group and ADI in Baltimore City. Top: social services density in the community using the facility address;

the neighborhood had to face. For instance, in Baltimore City, most of the social service facilities were in the center of the city while disadvantaged neighborhoods in east and west Baltimore lacked access to those services and had fewer households with internet access to search for such services in other neighborhoods.

Our findings revealed a higher demand for social services in disadvantaged neighborhoods; however, the demand for social services was potentially higher than what we identified in those neighborhoods. The digital divide and lack of internet access (to search for social services) in disadvantaged neighborhoods might have masked the actual demand for such services. Moreover, the lack of social services in the majority of disadvantaged neighborhoods in Maryland and Baltimore City might have resulted in an underrepresentation of the actual demand in those neighborhoods. In other words, when in need of a service people would search less for those services due to unavailability of such service in their neighborhood.

We assessed factors affecting the number of seekers of social services in Maryland in a GEE model. We did not perform the model for Baltimore City due to the small sample size across 25 unique ZIP codes with available data in Baltimore City. The model confirmed the results of the univariate analysis with disadvantaged neighborhoods (higher ADI) showing an increase in the number of searches for social services. Also, the increase in the social services density showed an increase in the number of searches. An increase in the number of households with internet access presented a decrease in the number of individuals seeking social services but the association was not statistically significant. Since we detected a highly negative correlation between ADI and
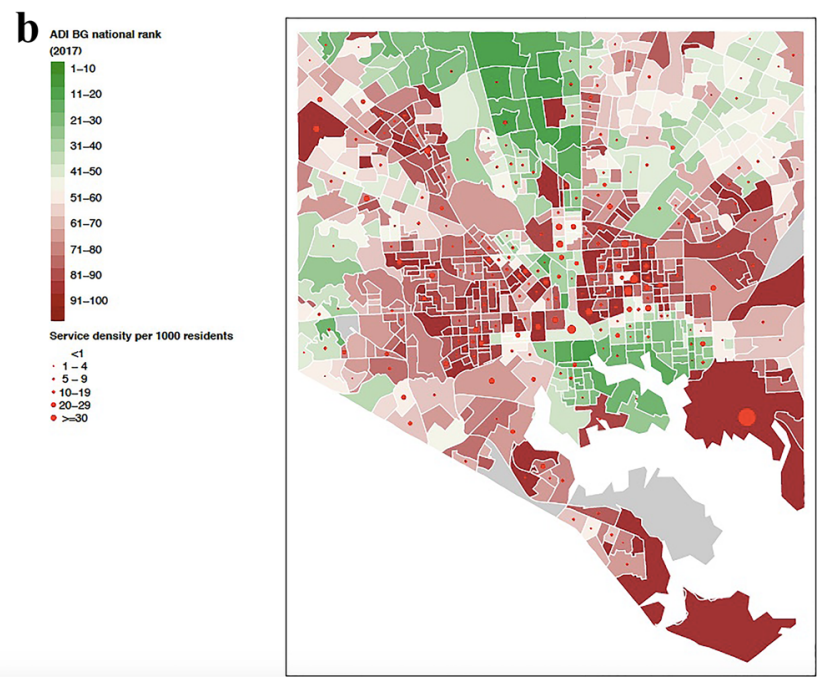

Bottom: social services diversity (e.g., housing, food, transportation) provided by all facilities in each block group

internet access (increase in ADI correlated with lower internet access) such correlation might play a role in the impact of internet access on the number of individuals seeking services. In other words, the increase in the number of households with internet access was a sign of a neighborhood's relative wealth; hence, individuals in those neighborhoods sought fewer social services.

The disparities in internet/eHealth access among residents of disadvantaged neighborhoods (i.e., high ADI percentiles) can also affect population health management efforts of healthcare providers [28]. This is stemmed from the fact that healthcare providers often face challenges with finding accessible data sources/platforms to identify highrisk patients and linking them to appropriate social services [29-31]. Given the increased adoption and maturation of EHRs and patient portals among healthcare providers [32, 33], health systems are increasingly using EHR-derived data to improve the management of their patient populations (e.g., risk stratification, care coordination) [34-39]. However, the lack of access to internet and eHealth tools such as patient portals among individuals residing in disadvantaged neighborhoods may lead to health systems having incomplete data on such patients hence creating potential disparities in identifying high-risk patients residing in such neighborhoods. Nevertheless, despite efforts in identifying social needs using EHRs [40-44], utilizing such information for managing risk is still uncommon in clinical practice $[31,44]$. Furthermore, in a broader context of population health, the lack of access to the internet, eHealth technologies, and the absence of social services in disadvantaged neighborhoods may limit public health departments to fully address the social needs of high-risk populations [45-47]. 
Calling digital divide a "super-determinant of health" shows its impact on the health of individuals and populations as without internet access a number of health and social services would be inaccessible to those in need.

\section{Public health implications}

Our study confirmed the findings of similar studies presenting the digital divide and its association with access to available community-based social services. Such findings would help policymakers to implement programs addressing the divide. For instance, a study in New York City by the city comptroller's office in 2015 identified about 813,000 households ( $26 \%$ of city population) lacking broadband access at home, from whom 510,000 ( 62.7\%) also did not have access to personal computers. The majority of those with a lack of broadband access were African Americans and Hispanics with less than a high school education [48]. Such lack of access would limit individuals' abilities to identify available social services in their neighborhoods. To address this issue, New York City launched LinkNYC in 2016 [49], an initiative to bring free internet to the entire city. Soon after, the city added Aunt Bertha [17] - an app to search for social safety-net services - to the initiative. The initiative aimed to empower vulnerable communities of New York City to search for social services available in the city [49]. A similar initiative would help other disadvantaged neighborhoods to get connected to community-based social services [45-47]. To fully address this issue social service organizations also need to become aware of how technology affects vulnerable populations and to develop solutions to address the digital divide. The training of social workers in technological intervention with client populations would help to equip them with new tools to access vulnerable populations and to empower them.

\section{Limitations}

Our study had several limitations. We did not have access to individual-level data on health outcomes or utilization of eHealth technology. The three major variables of ADI, internet access, and access to social services organizations were available at different geographic levels. For instance data on seeker and healthcare worker's search for social services were reported at ZIP code level. Therefore, the number of searches by a few patients or providers were attributed to the whole ZIP code. In our analysis, we reported each variable at the most geographically granular level (block group for ADI and social services, and census tract for internet access) so that the differences in the distribution of each variable would be visible among small geographic areas. Having access to data at different geographic levels for the three major variables limited our univariate analysis to higher geographic levels for each pair of datasets (Tables 1, 2 and $3)$. For instance, data on the number of searches by seekers and healthcare workers were available at a ZIP code level. Thus, we reported the number of searches for each ADI category on a ZIP code level. ZIP codes are large geographic areas enclosing several neighborhoods with different levels of socioeconomic challenges; hence, reporting the univariate results at a ZIP code level potentially masked some of the differences among smaller geographic areas in each ZIP code. Our GEE model was also at a ZIP code level and the same limitations would apply to our findings of the modeling analysis.

Furthermore, we only had access to data on available social services and search history through Aunt Bertha's platform. The platform is widely utilized by consumers and healthcare workers. The company has contracts with healthcare providers in Maryland. But the use of their platform in the healthcare setting is not limited to those contracted institutions. Their platform is publicly available and healthcare workers similar to individual seekers have access to the searching function of the platform. Nevertheless, Aunt Bertha is not the only available social service platform. Our results might have underrepresented the search history due to lack of information on other available platforms. Moreover, the Aunt Bertha platform contains a very wide range of social services in each neighborhood but the list is not exhaustive. Therefore, the dataset might have underrepresented the available social services.

\section{Conclusions and public health implications}

Despite the limitations of this study, we had access to a robust composite measure (i.e., ADI) presenting different socioeconomic characteristics of neighborhoods in Maryland and Baltimore City. The FCC data provided the marketlevel information about the number of actual connections being subscribed by households in a region, hence overcoming the limited number of participants responding to internet access surveys of past studies [11]. Using data on fixed internet access rather than broadband and/ or cellphone access as were reported in past studies $[22,26]$ helped us to reveal the immense disparities that currently exist in relation to connectivity and access to eHealth technology. Our study also provided an example of how to make use of FCC data, a less utilized data source in studies addressing the digital divide and its impact on health, linked to other data sources on SDOH and available community based social services and can be a model for future studies in this domain.

While our study was limited to Maryland and Baltimore City using available national data on socioeconomic characteristics of neighborhoods (i.e., ADI), FCC data on fixed internet access, and Aunt Bertha's data on access to 
community-based social services will provide the opportunity to replicate this assessment beyond Maryland and in other states at the neighborhood and regional level. The current COVID-19 pandemic and expanded services to address the pandemic such as the Emergency Broadband Benefit [50], an FCC program helping families and households struggling to afford internet service to get connected to jobs, critical healthcare services, and virtual classrooms, will provide other data sources for a more comprehensive assessment.

Future studies should assess the impact of the digital divide on the utilization of eHealth technology and its ultimate impact on health outcomes and healthcare utilization. Such an assessment would help to properly address the growing role of internet access in connecting patients to the care continuum. The current COVID-19 outbreak and the unprecedented shift to telehealth services remind us of the growing role of internet connectivity in the health of individuals and populations. The pandemic has revealed the urgency of considering internet access as an SDOH or a "super-determinant of health". The policymakers must propose policies to address the digital divide, in addition to other SDOH challenges, in disadvantaged communities experiencing the divide and other $\mathrm{SDOH}$ challenges.

Supplementary information The online version contains supplementary material available at https://doi.org/10.1007/s10916-021-01769-w.

Authors' contributions All authors contributed significantly to the project and writing of the manuscript. All authors reviewed the final paper and provided comments as deemed necessary. EH designed the overall scope and goals of the study. She supervised the study analysis, interpretation of the results, and led writing this paper. XM performed the data analysis and interpretation of the results. YSH supported EH in the selection of FCC data and variables and evaluation of the results. HK and JW contributed to setting the overall scope and goal of the project as well as finalizing the manuscript. DG was the principal investigator of the project and supervised the day-to-day operations of the project. We would like to thank Aunt Bertha for their support and for sharing their data on community-based organizations with our team for this project.

Funding Research reported in this publication was supported by the National Institute On Minority Health And Health Disparities of the National Institutes of Health under Award Number U54MD000214. The content is solely the responsibility of the authors and does not necessarily represent the official views of the National Institutes of Health.

Availability of data and material Data used in this study are publicly available at sources specified in the methods section.

\section{Declarations}

Ethical approval We did not obtain institutional review board approval due to the use of publicly available, de-identified data, per usual institutional policy. We obtained a data use agreement with Aunt Bertha to access their supply data.
Consent to participate Not Applicable.

Consent for publication Not Applicable.

Conflict of interest/competing interests None

\section{References}

1. Baum, F., Newman, L., Biedrzycki, K., Vicious cycles: Digital technologies and determinants of health in Australia. Health Promot Int. 29(2):349-360, 2014 Accessed 24 Jun 2019. https://doi. org/10.1093/heapro/das062.

2. 2016 broadband progress report., Federal Communications Commission Web site. https://www.fcc.gov/reports-research/reports/ broadband-progress-reports/2016-broadband-progress-report. Updated 2016. Accessed on 6 Jun 2021.

3. Congressional Research Service., Tribal broadband: Status of deployment and federal funding programs. https://fas.org/sgp/crs/misc/ R44416.pdf. Updated January 9, 2019. Accessed on 6 Jun 2021.

4. Pew Research Center - Internet \& Technology., Demographics of internet and home broadband usage in the united states I pew research center. 2019. https://www.pewinternet.org/fact-sheet/ internet-broadband/. Accessed on 6 Jun 2021.

5. West Darrell, M., Karsten, Jack., Rural and urban America divided by broadband access. 2016. https://www.brookings.edu/blog/techtank/ 2016/07/18/rural-and-urban-america-divided-by-broadband-access/. Accessed on 6 Jun 2021.

6. Johns Hopkins Coronavirus Resource Center. https://coronavirus. jhu.edu/map.html. Accessed on 6 Jun 2021.

7. Becker's Hospital Review., Led by COVID-19 surge, virtual visits will surpass 1B in 2020: report. https://www.beckershospitalreview. com/telehealth/led-by-covid-19-surge-virtual-visits-will-surpass1b-in-2020-report.html?origin=CIOE\&utm_source=CIOE\&utm_ medium=email. Accessed on 9 Jun, 2021.

8. American Medical Informatics Association., Request for comment - actions to accelerate adoption and accessibility of broadbandenabled health care solutions and advanced technologies (GN docket no. 16-46, FCC 17-46). https://www.amia.org/sites/default/files/ AMIA-Response-to-FCC-Notice-on-Accelerating-Broadband-HealthTech-Availability.pdf. Updated 2017. Accessed on 9 Jun 2021.

9. FCC tool examines broadband as 'superdeterminant' of health I public health newswire. 2016. http://www.publichealthnewswire. org/?p=15772. Accessed on 9 Jun 2021.

10. FCC - Connect2Health., Mapping broadband health in America 2017. https://www.fcc.gov/reports-research/maps/connect2health/ index.html \#ll=40,-95\&z=4\&t=health\&hhm=hh_obesity\&advbb= in_bb_access\$0_30\&dmf = none\&zlt=county. Updated 2017. Accessed on 9 Jun 2021.

11. Greenberg-Worisek, A. J., Kurani, S., Finney Rutten, L. J., Blake, K. D., Moser, R. P., Hesse, B. W., Tracking healthy people 2020 internet, broadband, and mobile device access goals: An update using data from the health information national trends ... - PubMed - NCBI. $J$. Med. Internet Res. 21(6):e13300, 2019.

12. The United States Census Bureau., American community survey (ACS). https://Www.census.gov/programs-surveys/acs/. Accessed on 9 Jun 2021.

13. Percent of population below the poverty level in Baltimore city, MD. FRED, Federal Reserve Bank of St. Louis Web site. https:// fred.stlouisfed.org/series/S1701 ACS024510. Updated 2019. Accessed on 9 Jun 2021.

14. Department of Medicine, University of Wisconsin, School of Medicine and Public Health. The neighborhood atlas. https:// 
www.neighborhoodatlas.medicine.wisc.edu. Updated 2019. Accessed on 9 Jun 2021.

15. Singh, G. K., Area deprivation and widening inequalities in US mortality, 1969-1998. Am. J. Public Health. 93(7):1137-1143, 2003. https://doi.org/10.2105/AJPH.93.7.1137.

16. Federal Communications Commission., Residential fixed internet access service connections per 1000 households by census tract. https://www.fcc.gov/reports-research/maps/. Updated 2016. Accessed on 9 Jun 2021.

17. Aunt Bertha., Connecting people and programs. https://Www. auntbertha.com. Accessed on 9 Jun 2021.

18. Zeger, S. L., Liang, K. Y., Longitudinal data analysis for discrete and continuous outcomes. Biometrics. 42(1):121-130, 1986.

19. Kulldorff, M., A spatial scan statistic. Communications in statistics-theory and methods. 26(6):1481-1469, 1997.

20. The R project for statistical computing. www.r-project.org. Accessed on 9 Jun 2021.

21. Office of Disease Prevention and Health Promotion, U. S. Department of Health and Human Services. Health communication and health information technology. https://www.healthypeople.gov/ 2020/topics-objectives/topic/health-communication-and-healthinformation-technology/objectives. Updated 2019. Accessed on 9 Jun 2021

22. Woods, S. S., Forsberg, C. W., Schwartz, E. C., et al. The association of patient factors, digital access, and online behavior on sustained patient portal use: A prospective cohort of enrolled users. - PubMed - NCBI. J. Med. Internet Res. 19(10):e345, 2017.

23. Statement of Chairman Tom Wheeler. https://docs.fcc.gov/public/ attachments/FCC-15-10A3.pdf. Accessed on 9 Jun 2021.

24. What is Fixed Wireless Internet Connection? https://www. meshtelco.com.au/what-is-fixed-wireless-internet-connection/. Accessed on 9 Jun 2021.

25. Cellular Network. https://en.wikipedia.org/wiki/Cellular_network. Accessed on 9 Jun 2021.

26. Ginossar, T., Predictors of online cancer prevention information seeking among patients and caregivers across the digital divide: A cross-sectional, correlational study. JMIR Cancer. 2(1):e2, 2016.

27. Department of Commerce, National Telecommunication and Information Administration. Partnership for progress on the digital divide. https://www.ntia.doc.gov/files/ntia/publications/ppdd-nbracomments. pdf. Updated. October 11, 2016. Accessed on 9 Jun 2021.

28. Kharrazi, H., Lasser, E. C., Yasnoff, W. A., et al. A proposed national research and development agenda for population health informatics: summary recommendations from a national expert workshop. J. Am. Med. Inform. Assoc. 24(1):2-12, 2017.

29. Hatef, E., Kharrazi, H., VanBaak, E., et al. A state-wide health IT infrastructure for population health: building a communitywide electronic platform for Maryland's all-payer global budget. Online J. Public Health Inform. 9(3): e195, 2017.

30. Hatef, E., Lasser, E. C., Kharrazi, H., et al. A Population health measurement framework: evidence-based metrics for assessing community-level population health in the global budget context. Popul. Health Manag. 21(4):261-270, 2018.

31. Hatef, E., Searle, K. M., Predmore, Z., et al. The impact of social determinants of health on hospitalization in the Veterans Health Administration. Am. J. Prev. Med. 6(6):811-818, 2019.

32. Kharrazi, H., Gonzalez, C.P., Lowe, K. B., et al. Forecasting the maturation of electronic health record functions among US hospitals: retrospective analysis and predictive model. J. Med. Internet Res. 20(8): 10458, 2018.

33. Patel, V., Johnson, C., Individual's use of online medical records and technology for health needs. The Office of National Coordinator. https://www.healthit.gov/sites/default/files/page/2018-03/HINTS2017-Consumer-Data-Brief-3.21.18.pdf. Accessed on 9 Jun, 2021.
34. Kharrazi, H., Chi, W., Chang, H. Y., et al. Comparing populationbased risk-stratification model performance using demographic, diagnosis and medication data extracted from outpatient electronic. Med. Care. 55(8):789-796, 2017.

35. Kharrazi, H., Weiner, J. P., A Practical comparison between the predictive power of population-based risk stratification models using data from electronic health records versus administrative claims: setting a baseline for future EHR-derived risk stratification models. Med. Care. 56(2):202-203, 2018.

36. Chang, H. Y., Richards, T. M., Shermock, K. M., et al. Evaluating the impact of prescription fill rates on risk stratification model performance. Med. Care. 55(12):1052-1060, 2017.

37. Lemke, K. W., Gudzune, K. A., Kharrazi, H., et al. Assessing markers from ambulatory laboratory tests for predicting highrisk patients. Am. J. Manag. Care. 24(6):e190-e195, 2018.

38. Kan, H. J., Kharrazi, H., Leff, B., et al. Defining and assessing geriatric risk factors and associated health care utilization among older adults using claims and electronic health records. Med. Care. 56(3):233-239, 2018.

39. Kharrazi, H., Chang, H. Y., Heins, S. E., et al. Assessing the impact of body mass index information on the performance of risk adjustment models in predicting health care costs and utilization. Med. Care. 56(12):1042-1050, 2018.

40. Hatef, E., Rouhizadeh, M., Tia, I., et al. Assessing the availability of data on social and behavioral determinants in structured and unstructured electronic health records: a retrospective analysis. JMIR Med. Inform. 7(3):e13802, 2019.

41. Chen, T., Dredze, M., Weiner, J. P., et al. Extraction of geriatric syndromes from electronic health record clinical notes: assessment of statistical natural language processing methods. JMIR Med. Inform. 7(1):e13039, 2019.

42. Kharrazi, H., Anzaldi, L. J., Hernandez, L., et al. The value of unstructured electronic health record data in geriatric syndrome case identification. J. Am. Geriatr. Soc. 66(8):1499-1507, 2018.

43. Chen, T., Dredze, M., Weiner, J. P., et al. Identifying vulnerable older adult populations by contextualizing geriatric syndrome information in clinical notes of electronic health records. J. Am. Med. Inform. Assoc. 26(8-9):787-795, 2019.

44. Daniel, H., Bornstein, S. S., Kane, G., Addressing social determinants to improve patient care and promote health equity: an American College of Physicians position paper. Ann. Intern. Med. 168(8):577-578, 2018.

45. Dixon, B. E., Kharrazi, H., Lehmann, H. P., Public health and epidemiology informatics: recent research and trends in the United States. Yearb. Med. Inform. 10(1):199-206, 2015.

46. Gamache, R., Kharrazi, H., Weiner, J. P., Public and population health informatics: the bridging of big data to benefit communities. Yearb. Med. Inform. 27(1):199-206, 2018.

47. Hatef, E., Weiner, J. P., Kharrazi, H., A public health perspective on using electronic health records to address social determinants of health: the potential for a national system of local community. Int. J. Med. Inform. 124:86-89, 2019.

48. Stringer Scott, M., Internet inequality: Broadband access in NYC. Office of the New York City Comptroller. https://comptroller. nyc.gov/reports/internet-inequality-broadband-access-in-nyc/. Updated December 7, 2014. Accessed on 9 Jun 2021.

49. Anzilotti, E., Showing New Yorkers the free wi-fi ropes. CityLab Web site. http://www.citylab.com/navigator/2016/08/tocourt-a-skeptical-public-new-york-sends-wi-fi-ambassadors/ 495623/. Accessed on 9 Jun 2021.

50. Federal Communications Commission., Emergency Broadband Benefit. https://www.fcc.gov/broadbandbenefit. Accessed on 10 Sept 2021.

Publisher's Note Springer Nature remains neutral with regard to jurisdictional claims in published maps and institutional affiliations. 


\section{Authors and Affiliations}

\section{Elham Hatef ${ }^{1,2}\left(\mathbb{0} \cdot\right.$ Xiaomeng Ma $^{1} \cdot$ Yahya Shaikh ${ }^{3} \cdot$ Hadi Kharrazi $^{1} \cdot$ Jonathan P. Weiner ${ }^{1} \cdot$ Darrell J. Gaskin $^{2}$}

1 Center for Population Health Information Technology, Department of Health Policy and Management, Johns Hopkins Bloomberg School of Public Health, Baltimore, MD, US

2 Johns Hopkins Center for Health Disparities Solutions, Baltimore, MD, US
3 Department of International Health, Johns Hopkins Bloomberg School of Public Health, Baltimore, MD, US 